\title{
Los principios \\ de transparencia \\ y publicidad como \\ herramientas de lucha \\ contra la corrupción \\ en la contratación \\ del Estado
}

Juan David Duque Botero'

\section{RESUMEN}

El presente artículo tiene como objetivo hacer un acercamiento al fenómeno de la corrupción y cómo este se relaciona con la contratación estatal en Colombia. En esa medida se pondrá de presente la importancia que adquiere el cumplimiento de los principios de publicidad y transparencia en la actividad contractual del Estado como una herramienta fundamental de lucha contra la

1 Doctor en Derecho de la Universidad Alfonso x El Sabio, Madrid, España. Máster en Derecho Administrativo de la Universidad del Rosario, Bogotá, Colombia. Se ha desempeñado como director de Colombia Compra Eficiente, secretario general del Ministerio de Tecnologías de la Información y las Comunicaciones (MinTIC) y magistrado auxiliar de la Sección Tercera del Consejo de Estado. Docente de Contratación Estatal de la Facultad de Jurisprudencia de la Universidad del Rosario, Bogotá, Colombia. Correo-e: jduque@ duquebotero.com. Enlace ORCID: https://orcid.org/0000-0002-5281-9793. Fecha de recepción: 10 de marzo de 2020. Fecha de modificación: 20 de abril de 2020. Fecha de aceptación: 2 de mayo de 2020. Para citar el artículo: Duque Botero, JuAn David, "Los principios de transparencia y publicidad como herramientas de lucha contra la corrupción en la contratación del Estado", Revista digital de Derecho Administrativo, Universidad Externado de Colombia, n. ${ }^{\circ}$ 24, 2020, pp. 79-101. DOI: https://doi.org/10.18601/21452946.n24.04. 
corrupción. Esto, toda vez que se permite a los interesados analizar la forma como las entidades gestionan y ejecutan los recursos públicos.

Palabras clave: contratación estatal, principio de publicidad, corrupción, derecho de acceso a la información, información pública, principio de transparencia.

\title{
The Principles of Transparency and Publicity as a Tool in the Fight Against Corruption
}

\author{
ABSTRACT
}

The present article aims to approach the concept of corruption and how it relates to public procurement in Colombia. To that extent, the research insists on the importance of compliance with the principles of publicity and transparency in the contractual activity of the State, as a crucial tool in the anti-corruption fight. This, given that it allows stakeholders to analyze how public entities manage and expend public resources.

Keywords: Public Contract, Principle of Publicity, Corruption, Information Access Right, Public Information, Principle of Transparency.

\section{INTRODUCCIÓN: EL CONCEPTO DE CORRUPCIÓN}

Para acercarse al concepto de corrupción es oportuno, en primer lugar, referirse a la definición de la palabra como "acción y efecto de corromper o corromperse $^{122}$; la corrupción se ha presentado como un fenómeno que no encuentra una definición o noción univoca en los ámbitos nacional e internacional y en ese sentido, diferentes autores presentan todo tipo de nociones dependiendo de la esfera con el que se relacionen. Como ejemplo de lo anterior, el exsecretario general de las Naciones Unidad Koffi Annan se ha referido a la corrupción como:

una plaga insidiosa que tiene un amplio espectro de consecuencias corrosivas para la sociedad. Socava la democracia y el Estado de derecho, da pie a violaciones de los derechos humanos, distorsiona los mercados, menoscaba la calidad de vida y permite el florecimiento de la delincuencia organizada, el terrorismo y otras amenazas a la seguridad humana ${ }^{3}$.

2 Real Academia Española, "corrupción". Disponible en línea: https://dle.rae.es/?w= corrupci\%C3\%B3n [fecha de consulta: 20 de febrero de 2020].

3 Organización de Nacionales Unidas, Oficio contra la Droga y el Delito, Nueva York: Convención de las Naciones Unidas Contra la Corrupción, 2004, p. 3. 
A su vez, Misas Arango sostiene que "La noción de corrupción es parasitaria de un sistema normativo. Por esa razón, la corrupción puede tener una naturaleza económica, política, jurídica o ética, o participar de estos niveles a la vez ${ }^{\prime \prime}$.

Otros autores se han ocupado de profundizar las formas en las que se manifiesta el fenómeno en estudio; por ejemplo, Marianao Cartolano Schiaffino establece que no es posible definir de la misma manera la corrupción como un fenómeno en relación con el acto de corrupción en sí mismo, y en ese sentido, define un acto de corrupción como aquel en el que "una persona obligada moral o legalmente hacia un interés ajeno (público o privado), lo pospone en función de un interés propio o de tercero" ${ }^{15}$. En síntesis, la corrupción es un fenómeno dinámico que puede afectar los sistemas económicos ${ }^{6}$, políticos $^{7}$, jurídicos y sociales de forma individual o conjunta; es decir, que se presenta como un fenómeno multidisciplinario, a la vez la definición de la corrupción se presentará diferente desde los sistemas mencionados según el grado en que afecte la materia especifica a investigar. Una vez establecido el concepto, se estudia cómo se manifiesta el fenómeno en Colombia.

\section{LA CORRUPCIÓN EN COLOMBIA}

En el año 2019, la Organización por la Transparencia Internacional realizó una encuesta sobre corrupción a personas mayores de edad en 18 países de América Latina y el Caribe. Los resultados arrojados para Colombia dejan al país en el ranking de percepción de corrupción en el puesto número 97 de 180 países; al respecto, conviene resaltar que, del total de encuestados, el 52\% considera que la corrupción aumentó en los 12 meses anteriores a la realización de la encuesta ${ }^{8}$. No fueron más alentadores los resultados del sondeo en materia de percepción de corrupción en el sector público, pues los encuestados consideran que la mayoría de los funcionarios que trabajan en las instituciones del Estado son corruptos, Transparencia Internacional presentó un comparativo de las cifras obtenidas en 2017 con las obtenidas en 2019, a saber:

4 Gabriel Misas Arango, La lucha anticorrupción en Colombia, Bogotá: Contraloría General de la República, 2005, p. 23.

5 Mariano J. Cartolano Schiaffino, La corrupción: aproximación teórica, Bogotá: Leyer, 2009, p. 20 .

6 Kimberly Ann Elliott, La corrupción en la economía global, México: Editorial Limusa, 2001.

7 Francisco J. Laporta y Silvina Álvarez, La corrupción política, Madrid: Alianza Editorial, 1997, pp. 77-90.

8 Coralie Pring y Jon VRuSHI, Barómetro global de la corrupción América Latina y el Caribe 2019 Opiniones y experiencias de los ciudadanos en materia de corrupción, Transparency International, 2019. Disponible en línea: https://transparenciacolombia.org.co/wp-content/uploads/ gcb-lac-report-web.pdf [fecha de consulta: 18 de febrero de 2020]. 


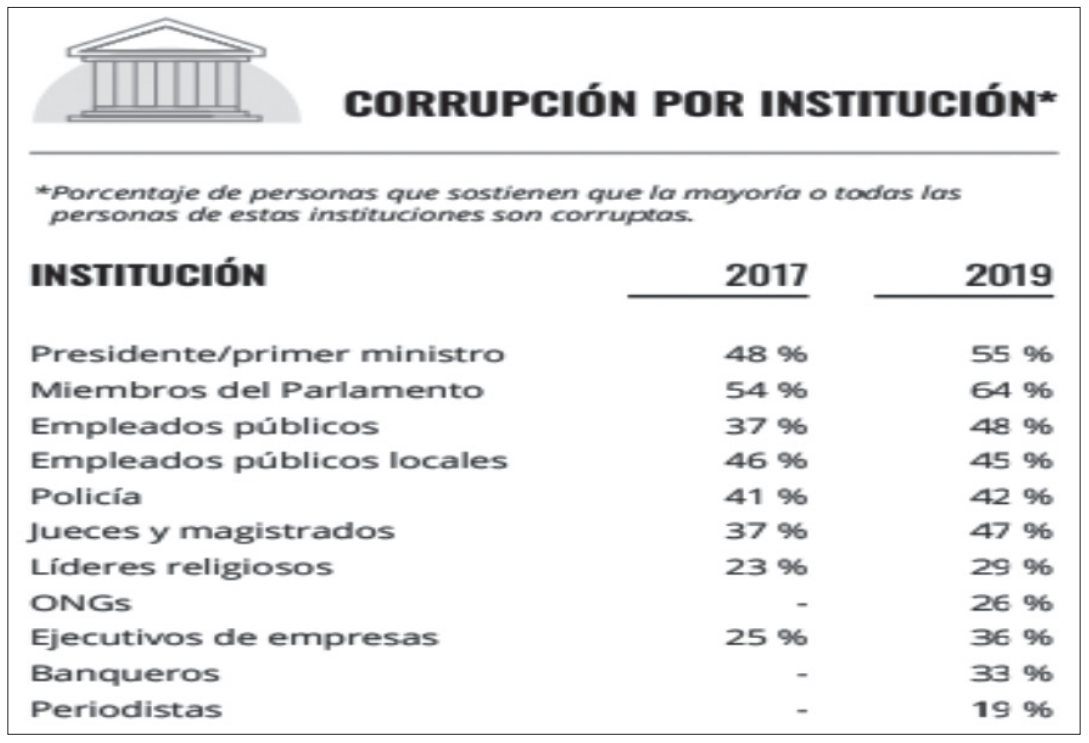

Fuente: Transparencia Internacional ${ }^{9}$.

De lo anterior es posible concluir que los ciudadanos, en general, tienen una alta percepción de corrupción en el país, percepción que afecta la confianza en las instituciones oficiales y de los funcionarios que las representan ${ }^{10}$.

Robert Klitgaard ${ }^{11}$ establece que los escenarios de corrupción se presentan con mayor frecuencia cuando: a) los agentes del Estado gozan de arbitrio y tienen un bajo nivel de responsabilidad ${ }_{i}$ b) existen bajas probabilidades de que el agente sea descubierto y sancionado de manera rápida y eficiente; c) el agente tiene un salario bajo; d) el agente posee poder amplio sobre el "cliente", e) existe un bajo costo moral por aceptar sobornos, es decir, dar o recibir sobornos está generalmente aceptado $;$ f) no existe una conciencia de satisfacción o beneficio por ser honesto $;$ y g) el costo beneficio que representa el acto de corrupción en el agente es mucho mayor que el de ser honesto o actuar conforme a la norma.

Vivian Newman y María Paula Ángel presentan como elementos esenciales de la corrupción "i) el abuso o desviación del poder encomendado, que puede ser público o privado; ii) el beneficio o ganancia privada, que puede ser personal o para un tercero, y que no necesariamente tiene que ser monetaria"12. En otras palabras, las funciones que una determinada persona desempeña en

$9 \quad$ Ibíd.

10 Fernando Cepeda Ulloa, La corrupción administrativa en Colombia diagnóstico y recomendaciones para combatirla, Bogotá: Contraloría General de la República, 1994.

11 Robert Klitgaard, Controlling corruption, Berkeley: University of California Press, 1988.

12 Vivian Newman Pont y María Paula Ángel Arango, Estado del arte sobre la Corrupción en Colombia, Bogotá: Dejusticia, 2017, p. 15. 
su empleo, ya sea en el sector público o privado, serán susceptibles de ser corruptibles por el solo hecho de tener de alguna manera un poder de decisión respecto de las actividades que desempeñe; adicional a ello, se aprecia con absoluta claridad que el factor económico no será en todos los casos el factor determinante para adelantar el acto corrupto, pues el "beneficio" se concreta en diversas formas. Ahora bien, en relación con los escenarios susceptibles de corrupción presentados por Klitgaard ${ }^{13}$ y de los elementos esenciales de la corrupción que establecen Newman y Ángel ${ }^{14}$, se precisa que el fenómeno de la corrupción en Colombia se presenta especial, diferente y con un grado de complejidad mayor al que se presenta respecto a otros países de la región.

Diferentes doctrinantes dan cuenta en sus escritos de la debilidad institucional que caracteriza a Colombia, esto por cuanto ha sido imposible que el Estado se desprenda de las estructuras de poder que hacen predominar los intereses privados de unos pocos. Ese fenómeno de debilidad institucional repercute de forma casi directa en la legitimidad de las instituciones, es decir, los ciudadanos en general no creen que si cometen actos de corrupción puedan, en primer lugar, ser descubiertos y en caso de que así sea, no creen que la sanción impuesta represente un costo más alto que el beneficio que le otorga el acto corrupto.

Históricamente en Colombia, el narcotráfico y la violencia de grupos armados al margen de la ley, así como la eterna congestión que presenta el sistema de administración de justicia, estos tres factores potencian los escenarios que describe Robet Klitgaard ${ }^{15}$. Al respecto, Fernando Cepeda Ulloa considera igualmente que existen nueve factores que contribuyen permanentemente a propiciar comportamientos corruptos, los enumera así: a) enriquecimiento del país; b) crisis del sistema tradicional de valores; c) el fraccionamiento y debilitamiento de los partidos políticos; d) ineficacia del poder judicial; e) el impacto del negocio criminal de las drogas ilícitas; f) descentralización sin controles; $\mathrm{g}$ ) La financiación de la política h) debilidad de la oposición; e i) la debilidad del gobierno ${ }^{16}$.

En suma, dada la multiplicidad de factores antes descritos se potencian los escenarios de corrupción y alimentan las estructuras corruptivas, permitiéndoles permear los sistemas político, jurídico, económico y social de manera integral y dinámica. Esto no es poco, se tiene presente como lo dice Leonardo Tovar que las prácticas corruptas

destruyen la dignidad y la libertad de las personas convirtiendo a quienes son sujetos de derechos en objetos de intercambio mercantil. La asignación fraudulenta 
de los recursos del país a los servidores públicos y a sus beneficiarios usurpa los medios necesarios para promover el bienestar de la población y ahonda así la injusticia social ${ }^{17}$.

Con la expedición de la Constitución de 1991, en Colombia se comenzaron a proferir una serie de normas que tenían como objeto último adoptar prácticas de bueno gobierno para tener una administración más eficiente y transparente, que no permitieran la actividad corrupta o que de alguna manera aminoraran el riesgo de presencia de actividades corruptivas en la Administración ${ }^{18}$. En efecto, la Constitución de 1991 incluyó ejemplos claros de estas disposiciones, así: el derecho de petición (artículo 23$)^{19}$, la responsabilidad patrimonial de los empleados públicos (artículo 90) ${ }^{20}$ y las disposiciones contenidas en el capítulo 2 del título 5 referentes a la función pública (artículos 122, 123, 124, $125,126,127,128$ y 129). También se incluyó ejemplos sobre la consagración de la pérdida de investidura a los congresistas (artículos 183 y 184), la función administrativa al servicio de los intereses generales (artículo 209) y la vigilancia de la gestión pública (artículo 270). A partir de ahí, la expedición de normas tendientes a fortalecer las dinámicas de la Administración proliferó, de manera que es variopinto el escenario normativo existente en Colombia. A continuación, se presenta un breve recuento de las normas que por la materia a la que se refieren se posicionan con algún grado de importancia en relación con la lucha contra la corrupción en el país.

Con la Ley 80 de 1993, el Congreso de la Republica expidió el Estatuto General de Contratación de la Administración Pública, y este, desde el principio, ha sido considerado un estatuto de principios que busca guiar la actividad contractual de las entidades del Estado y que tiene como principios rectores de la actividad contractual la transparencia, economía y responsabilidad. Por

17 Leonardo Tovar González, Ética social y corrupción pública. La corrupción en Colombia, Bogotá: Red de Solidaridad Social, 1997, pp. 32-36.

18 Mauricio Cárdenas y Roberto Steiner, Corrupción, crimen y justicia. Una perspectiva económica, Bogotá: Tercer Mundo Editores, 1998

19 Constitución Política de Colombia, artículo 23: "Toda persona tiene derecho a presentar peticiones respetuosas a las autoridades por motivos de interés general o particular y a obtener pronta resolución. El legislador podrá reglamentar su ejercicio ante organizaciones privadas para garantizar los derechos fundamentales". Disponible en línea: http://www. secretariasenado.gov.co/senado/basedoc/constitucion_politica_1991.html\#23 [fecha de consulta: 27 de febrero de 2020].

20 Constitución Política de Colombia, artículo 90: "El Estado responderá patrimonialmente por los daños antijurídicos que le sean imputables, causados por la acción o la omisión de las autoridades públicas. En el evento de ser condenado el Estado a la reparación patrimonial de uno de tales daños, que haya sido consecuencia de la conducta dolosa o gravemente culposa de un agente suyo, aquél deberá repetir contra este". Disponible en línea: http:// www.secretariasenado.gov.co/senado/basedoc/constitucion_politica_1991.html\#90[fecha de consulta: 27 de enero de 2020]. 
su parte, la Ley 190 de $1995^{[21]}$ contiene el régimen de los servidores públicos y la declaración de bienes y rentas de los funcionarios entre otras ${ }^{22}$. En el mismo año, el Decreto 250 dispuso la aprobación del Plan de Transparencia "Para Volver a Creer", así como la creación del Consejo Nacional Transparente. Este Plan de Transparencia era un programa de la Presidencia de la República que tenía como objetivo recuperar la credibilidad ciudadana en el Estado colombiano, adelantando acciones para garantizar la participación ciudadana con la finalidad de que las autoridades administrativas cumplieran con los principios de la función pública y adelantar la lucha contra la corrupción.

Los decretos $1477^{[23]}$ y 2232 de $1995^{[24]}$ reglamentaron respectivamente lo correspondiente a la publicación de contratos en el Diario Único de Contratación Pública y la declaración de bienes y rentas e informe de actividad económica, respectivamente. A saber, el artículo 1 del Decreto 1477 de 1995 estableció los parámetros para la comparación de ofertas en la contratación pública, y en ese sentido, era necesario crear en todo contrato que celebrara una entidad un anexo en el que se incluía la siguiente información: a) contratante, b) contratista, c) clase de contrato, d) objeto del contrato, e) obligaciones del contratista directamente relacionadas con el cumplimiento del objeto, f) valor, incluyendo valores unitarios, g) plazo o plazos para el cumplimiento de las obligaciones relacionadas con el objeto, h) número del contrato y su fecha de celebración, i) si existiere, nombre e identificación del interventor, y j) la indicación de si el valor del contrato supera el 50\% de la menor cuantía de la entidad contratante.

El Estatuto de la Administración de Justicia fue adoptado mediante la Ley 270 de 1996, y luego, mediante la Ley 412 de 1997, fue aprobada la Convención Interamericana contra la Corrupción. En esta oportunidad, el Estado colombiano se comprometió a adoptar como medidas preventivas la previstas en el artículo 3 de dicha convención ${ }^{25}$. En 1998 se profirió la Ley 489, que

21 Ley 190 de 1995, por la cual se dictan normas tendentes a preservar la moralidad en la Administración pública y se fijan disposiciones con el objeto de erradicar la corrupción administrativa.

22 Edgar Escobar LÓPEZ, Estatuto anticorrupción Ley 190 de 1995. Estudio técnico-jurídico integro, Medellín: Biblioteca Jurídica Diké, 1996.

23 Decreto 1477 de 1995, por el cual se reglamenta la Ley 190 del 6 de junio de 1995 en materia de publicación de contratos en el Diario Único de Contratación Pública.

24 Decreto 2232 de 1995, por medio del cual se reglamenta la Ley 190 de 1995 en materia de declaración de bienes y rentas e informe de actividad económica y así como el sistema de quejas y reclamos.

25 Ley 412 de 1997, por la cual se aprueba la Convención Interamericana contra la Corrupción, suscrita en Caracas el 29 de marzo de 1996, artículo 3: "Medidas preventivas. A los fines expuestos en el artículo 2. ${ }^{\circ}$ de esta Convención, los Estados Partes convienen en considerar la aplicabilidad de medidas, dentro de sus propios sistemas institucionales, destinadas a crear, mantener y fortalecer:

1. Normas de conducta para el correcto, honorable y adecuado cumplimiento de las funciones públicas. Estas normas deberán estar orientadas a prevenir conflictos de intereses 
tuvo por objeto regular el ejercicio de la función administrativa, determinar la estructura y definir los principio y reglas básicas de la organización y funcionamiento de la Administración pública ${ }^{26}$.

Siguiendo con esta evolución normativa, para el año 2000, mediante la Ley 610, se estableció el trámite para adelantar los procesos de responsabilidad fiscal de competencia de las contralorías, de manera pues que a través de estos procesos se determina la responsabilidad fiscal de los servidores públicos y los particulares que ejercen funciones públicas cuando, en ejercicio de estas, causen por acción u omisión y en forma dolosa o culposa un daño al patrimonio público ${ }^{27}$

y asegurar la preservación y el uso adecuado de los recursos asignados a los funcionarios públicos en el desempeño de sus funciones. Establecerán también las medidas y sistemas que exija a los funcionarios públicos informar a las autoridades competentes sobre los actos de corrupción en la función pública de los que tengan conocimiento. Tales medidas ayudarán a preservar la confianza en la integridad de los funcionarios públicos y en la gestión pública. 2. Mecanismos para hacer efectivo el cumplimiento de dichas normas de conducta.

3. Instrucciones al personal de las entidades públicas, que aseguren la adecuada comprensión de sus responsabilidades y las normas éticas que rigen sus actividades.

4. Sistemas para la declaración de los ingresos, activos y pasivos por parte de las personas que desempeñan funciones públicas en los cargos que establezca la ley y para la publicación de tales declaraciones cuando corresponda.

5. Sistemas para la contratación de funcionarios públicos y para la adquisición de bienes y servicios por parte del Estado que aseguren la publicidad, equidad y eficiencia de tales sistemas. 6. Sistemas adecuados para la recaudación y el control de los ingresos del Estado, que impidan la corrupción.

7. Leyes que eliminen los beneficios tributarios a cualquier persona o sociedad que efectúe asignaciones en violación de la legislación contra la corrupción de los Estados Partes.

8. Sistemas para proteger a los funcionarios públicos y ciudadanos particulares que denuncien de buena fe actos de corrupción, incluyendo la protección de su identidad de conformidad con su Constitución y los principios fundamentales de su ordenamiento jurídico interno.

9. Órganos de control superior, con el fin de desarrollar mecanismos modernos para prevenir, detectar, sancionar y erradicar las prácticas corruptas.

10. Medidas que impidan el soborno de funcionarios públicos nacionales y extranjeros, tales como mecanismos para asegurar que las sociedades mercantiles y otros tipos de asociaciones mantengan registros que reflejen con exactitud y razonable detalle la adquisición y enajenación de activos, y que establezcan suficientes controles contables internos que permitan a su personal detectar actos de corrupción.

11. Mecanismos para estimular la participación de la sociedad civil y de las organizaciones no gubernamentales en los esfuerzos destinados a prevenir la corrupción.

12. El estudio de otras medidas de prevención que tomen en cuenta la relación entre una remuneración equitativa y la probidad en el servicio público".

26 Ley 489 de 1998, por la cual se dictan normas sobre la organización y funcionamiento de las entidades del orden nacional, se expiden las disposiciones, principios y reglas generales para el ejercicio de las atribuciones previstas en los numerales 15 y 16 del artículo 189 de la Constitución Política y se dictan otras disposiciones.

27 Ley 610 de 2000, por la cual se establece el trámite de los procesos de responsabilidad fiscal de competencia de las contralorías. 
Después, por medio de la Ley 678 de 2001 y con ocasión de la ley antes citada, se determinó la regulación de la responsabilidad patrimonial de los servidores y exservidores públicos, así como de los particulares en ejercicio de funciones públicas a través del ejercicio de la acción de repetición o de llamamiento en garantía con fines de repetición. El Código Único Disciplinario fue expedido mediante la Ley 734 de 2002.

Posteriormente, para el año 2002, la Directiva presidencial n. ${ }^{\circ} 12$ de 2002 fijó los lineamientos, criterios, medidas y acciones de corto y mediano plazo que debían cumplir las entidades públicas en materia de lucha contra la corrupción en la contratación estatal.

Luego, el Documento Conpes 3249 de 2003 determinó una política de contratación de la Administración y se hicieron recomendaciones en relación con la creación de un sistema electrónico, que permitiera hacer el seguimiento de todas las etapas del proceso contractual. Una de las recomendaciones específicas para llevar a cabo una modificación a la Ley 80 de 1993 fue la de implementar los instrumentos que permitieran a las entidades cumplir con las obligaciones de publicidad de los procesos de selección ${ }^{28}$.

Otra norma expedida que tenía por finalidad la lucha contra la corrupción, teniendo como objetivo regular el empleo público, la carrera administrativa y la gerencia pública, fue la Ley 909 de 2004. Posteriormente, y de conformidad con los compromisos internacionales adquiridos por Colombia, fue expedida la Ley 970 de 2005, mediante la cual se adoptó en el ordenamiento jurídico colombiano la Convención de las Naciones Unidas contra la Corrupción.

Una de las normas más importantes en el Sistema de Compra Pública es la Ley 1150 de 2007, ya que por medio de esta ley se introdujeron medidas que permitieron generar eficiencia y transparencia en las disposiciones ya establecidas en la Ley 80 de 1993. Posteriormente, la Ley 1474 de 2011 previó las normas orientadas a fortalecer los mecanismos de prevención, investigación y sanción de actos de corrupción y la efectividad del control de la gestión pública.

En 2011 se creó también la Agencia Nacional de Contratación Pública Colombia Compra Eficiente mediante el Decreto 4170. Allí se determinó que dicha unidad administrativa especial sería el ente rector en materia de contratación pública. Su objetivo principal es desarrollar e impulsar políticas públicas y herramientas orientadas a la organización y articulación de los partícipes

28 Consejo Nacional de Política Económica y Social República de Colombia - Departamento Nacional de Planeación, Documento Conpes 3249 de 20 de octubre de 2003, "Los mecanismos e instrumentos por medio de los cuales las entidades cumplirán con las obligaciones de publicidad de los procesos de selección serán señalados por el Gobierno Nacional, de forma tal que la información tenga una divulgación adecuada, en todos los niveles para que además los medios que se deban utilizar guarden congruencia con el entorno en donde se produce la información". 
en los procesos de compras y contratación pública, esto con el fin de lograr una mayor eficiencia, transparencia y optimización de los recursos del Estado.

Asimismo, el Decreto 4637 de 2011 suprimió el Programa Presidencial de Modernización Eficiencia, Transparencia y Lucha contra la Corrupción, y creó en su lugar, en el Departamento Administrativo de la Presidencia de la República, la Secretaría de Transparencia, dependencia que asumió la competencia de elaborar la estrategia de lucha contra la corrupción.

Para el año 2012 se expidió el Decreto Ley 019; la finalidad de dicha disposición era, entre otros, la de suprimir trámites y procedimientos que resultaran innecesarios en la Administración pública; en consecuencia, esto permitiría que los ciudadanos pudieran acceder de manera mas sencilla a la información que necesitaran.

En la Ley 1712 de 2014, que creó la Ley de Transparencia y del Derecho de Acceso a la Información Pública Nacional y dictó otras disposiciones, se adoptaron diferentes medidas para obligar a las entidades del Estado a publicar la información de la actividad contractual que llevaran a cabo. Posteriormente se expidió la Ley 1577 de 2015, en la que se reguló el derecho fundamental al derecho de petición ante autoridades de manera general y especial.

La reglamentación de la Ley 1712 de 2015 se dio en el Decreto 103 del mismo año. Allí se fijaron las directrices generales para la publicación de la información pública, la gestión de solicitudes de información pública -transparencia pasiva-, la gestión de la información clasificada y reservada, y los instrumentos de la gestión de la información pública.

Ese mismo año, el Gobierno Nacional, en un importante esfuerzo por concentrar la información un solo cuerpo normativo que permitiera tener certeza y confianza en virtud del alto volumen de disposiciones en los diferentes sectores, ordenó la compilación de las disposiciones de carácter reglamentario vigentes en los sectores de la Administración pública nacional. Por la materia que nos ocupa, son los Decreto 1081 y 1082 de 2015 los que en este punto interesan.

Así, el Decreto 1081 de 2015 compiló las normas del sector de la Presidencia de la República, y, por su parte, el Decreto 1082 se refiere a disposiciones reglamentarias del sector Administrativo de Planeación Nacional.

Ahora bien, en materia penal, los esfuerzos no fueron diferentes. En el año 2000, con la expedición de la Ley 599 (Código Penal), se tipificaron una serie de conductas denominadas como "delitos contra la Administración pública". Estos son: a) peculado ${ }^{29}$, b) concusión ${ }^{30}$, c) cohecho ${ }^{31}$, d) celebración indebida

30 Ley 559 de 2000, artículo 404: "El servidor público que abusando de su cargo o de sus funciones constriña o induzca a alguien a dar o prometer al mismo servidor o a un tercero, dinero o cualquier otra utilidad indebidos, o los solicite, incurrirá en prisión de seis (6) a diez (10) años, multa de cincuenta (50) a cien (100) salarios mínimos legales mensuales 
de contratos ${ }^{32}$, e) tráfico de influencias ${ }^{33}$, f) enriquecimiento ilícito ${ }^{34}, \mathrm{~g}$ ) prevaricato $^{35}$, h) abuso de autoridad ${ }^{36}$, i) usurpación y abuso de las funciones públicas ${ }^{37}, \mathrm{j}$ ) delitos contra los servidores públicos ${ }^{38}, \mathrm{y}$ k) utilización indebida de información y de influencias derivadas del ejercicio de función pública ${ }^{39}$.

En definitiva, de las normas antes mencionadas, es claro que no todas tienen como objetivo principal la lucha contra la corrupción, sin embargo, la aplicación efectiva de esas disposiciones se traduce en la disminución de escenarios corruptibles. Ejemplos de ello pueden ser la implementación del Diario Único de Contratación Pública y la creación de parámetros para que la comparación de ofertas en la contratación pública propenda por la adecuada gestión de los recursos públicos, por la garantía de acceso a la información de todas las personas que estén interesadas en los procesos para participar o para realizar el seguimiento de estos, y también propenda por el cumplimiento de los principios de transparencia y publicidad. En suma, todo lo anterior se configura como una garantía, cuando menos, en la disminución de escenarios de corrupción.

\subsection{LA CORRUPCIÓN EN LA CONTRATACIÓN}

El artículo 2. ${ }^{\circ}$ de la Constitución Política consagra los fines esenciales del Estado tales como

servir a la comunidad, promover la prosperidad general y garantizar la efectividad de los principios, derechos y deberes consagrados en la Constitución, facilitar la participación de todos en las decisiones que los afectan y en la vida económica, política, administrativa y cultural de la Nación, defender la independencia nacional,

vigentes, e inhabilitación para el ejercicio de derechos y funciones públicas de cinco (5) a ocho (8) años".

31 Ley 599 de 2000, artículos 405 a 407.

32 Ley 599 de 2000, artículo 408 a 410 a.

33 Ley 599 de 2000, artículo 411 a 411 a.

34 Ley 599 de 2000, artículo 412: "Enriquecimiento ilícito. El servidor público, o quien haya desempeñado funciones públicas, que durante su vinculación con la administración o dentro de los cinco (5) años posteriores a su desvinculación, obtenga, para sí o para otro, incremento patrimonial injustificado, incurrirá, siempre que la conducta no constituya otro delito, en prisión de nueve (9) a quince (15) años, multa equivalente al doble del valor del enriquecimiento sin que supere el equivalente a cincuenta mil (50.000) salarios mínimos legales mensuales vigentes, e inhabilitación para el ejercicio de derechos y funciones públicas de noventa y seis (96) a ciento ochenta (180) meses". 
mantener la integridad territorial y asegurar la convivencia pacífica y la vigencia de un orden justo ${ }^{40}$.

En ese sentido, es a la Administración pública a quien le corresponde garantizar el cumplimiento de los fines esenciales del Estado mediante la contratación de bienes, obras y servicios. La Corte Constitucional señaló en la sentencia C-449 de 1992 que el objeto de los contratos que celebran las entidades es el de adquirir de forma legal y eficaz los bienes y servicios que necesitan; a saber, señaló:

Para el cumplimiento de los fines del Estado es necesario el aprovisionamiento de bienes y servicios por parte de los órganos públicos mediante la contratación. Luego, el objeto de lo contratos no es otro que la adquisición en forma legal, armónica y eficaz. Es por ello que el estudio y la comprensión de la contratación estatal debe inscribirse en los principios axiológicos del Estado social de derecho irradian todas las disposiciones contractuales previstas en la Constitución ${ }^{41}$.

La actividad contractual de la Administración se ha convertido en el punto de encuentro entre el Estado mismo y los particulares; para ello, es necesario generar confianza, seguridad y legitimidad de las actuaciones que se llevan a cabo. Enrique Gil Botero sostiene que la actividad contractual del Estado:

Es una realidad incuestionable, [...] que la Administración pública para la realización de los fines que el ordenamiento jurídico le asigna al Estado, no solamente adquiere los bienes y servicios que requiere mediante la técnica de los actos administrativos $[\ldots]$, sino que cada vez, con mayor frecuencia, interviene en el tráfico jurídico a través de la institución contractual ${ }^{42}$.

En pocas palabras, para garantizar el aprovisionamiento de bienes y servicios a los ciudadanos, la Administración está llamada a ejecutar los recursos que tiene a su cargo; es por eso que necesita la colaboración de los particulares, y producto de esa necesidad surge la relación contractual entre el particular y la Administración ${ }^{43}$. Al respecto, en sentencia C-932 de 2007, la Corte Constitucional reconoce la finalidad del contrato estatal, la importancia implícita de la actividad contractual y el rol indispensable del particular que contrata con la Administración. En ese sentido, la Corte expresó:

40 Constitución Política de Colombia, artículo 2.

41 Corte Constitucional, Sala Plena, sentencia C-449 del 9 de julio de 1992, expediente D-033.

42 EnRiQue Gil Botero, Teoría general de los contratos de la Administración pública, Bogotá: Legis, 1999 , p. 8 .

43 Corte Constitucional, Sala Plena, sentencia C-207 del 16 de mayo de 2019, expediente D-12877. 
el contrato público es uno de aquellos instrumentos jurídicos de los que se vale el Estado para cumplir sus finalidades, hacer efectivos los deberes públicos y prestar los servicio a su cargo, con la colaboración de los particulares a quienes corresponde ejecutar, a nombre de la administración, las tareas acordadas ${ }^{44}$.

El Congreso de la República aprobó el Presupuesto General de la Nación por un valor de 258,9 billones de pesos para la vigencia 2019; para gastos de funcionamiento se asignaron 160,2 billones de pesos, para gastos de inversión se destinaron 46,8 billones de pesos y, por último, para el pago de la deuda pública fueron destinados 1,9 billones de pesos ${ }^{45}$. Estas cifras permiten dimensionar la razón por la que las estructuras corruptas tienen como foco de su actividad el sector público.

En virtud de la gran cantidad de recursos que se mueven con ocasión de la celebración de contratos estatales, como por ejemplo en la vigencia 2019 , en la que las entidades del Estado celebraron 1.263.058 contratos de acuerdo con las cifras registradas por el Sistema de Contratación Pública Secop I y II. Por lo anterior, es meridianamente claro que la contratación del Estado será un foco de ataque crítico e impetuoso por parte de las estructuras corruptas ${ }^{46}$.

Consecuencia de la forma como la corrupción aqueja la contratación pública, Castro Cuenca se ha encargado de definir el concepto de corrupción en la contratación pública así:

La corrupción en la contratación pública puede definirse como la desviación del interés público, que se desarrolla a través del abuso del cargo, con el fin de obtener un beneficio extraposicional en cualquier acuerdo de voluntades celebrado por una Administración pública con los particulares ${ }^{47}$.

A la vez, identifica que son tres los elementos que componen la corrupción en cada una de las fases de la contratación pública: a) un elemento interno, que se manifiesta en la formación de la voluntad de la Administración "hay corrupción cuando el interés personal de quien toma decisiones en el ámbito público sustituye la objetividad en el ejercicio del poder"; b) un elemento adjetivo, donde se presenta el abuso del poder, que implica la expedición de actos administrativos precontractuales irregulares o la celebración misma de contratos estatales corruptos; y c) un aspecto material, que se da en la etapa

44 Corte Constitucional, Sala Plena, sentencia C-932 del 9 de noviembre de 2007, expediente D-6794.

45 Ley 1940 de 2018, por la cual se decreta el presupuesto de rentas y recursos de capital y ley de apropiaciones para la vigencia fiscal del 1. ${ }^{\circ}$ de enero al 31 de diciembre de 2019.

46 FedesarRollo, óp. cit.

47 Carlos Guillermo Castro Cuenca, Corrupción y delitos contra la Administración pública, Bogotá: Universidad del Rosario, 2009, pp. 27-83. 
de ejecución del contrato y que tiene como finalidad obtener beneficios a cargo del presupuesto público ${ }^{48}$.

Respecto de los elementos precedentes, conviene precisar en relación con el elemento interno que no siempre la corrupción se presenta per se desde el interior o con participación de funcionarios de las entidades; el elemento adjetivo señala la expedición de actos administrativos precontractuales irregulares o la celebración misma de contratos corruptos, sin embargo, una vez más, es necesario precisar que el solo hecho de que un contrato se vea afectado por actos de corrupción no lleva implícita la presunción de participación de un funcionario.

\section{EL PAPEL DE LOS PRINCIPIOS DE TRANSPARENCIA Y DE PUBLICIDAD EN EL MARCO DE LA CONTRATACIÓN PÚBLICA}

La Ley 80 de 1993 es conocida como un estatuto de principios que orientan la actividad contractual de las entidades del Estado sometidas al Estatuto General de Contratación de la Administración pública. El artículo 23 establece que "las actuaciones de quienes intervengan en la contratación estatal se desarrollarán con arregla a los principios de transparencia, economía y responsabilidad y de conformidad con los postulados que rigen la función administrativa".

En consecuencia, son conocidos como principios rectores de la contratación estatal transparencia, economía y responsabilidad. No obstante, la Ley 80 establece que la aplicación de las disposiciones contenidas en ese cuerpo normativo estará igualmente sometida a los principios de la función administrativa, como lo son igualdad, moralidad, eficacia, economía, celeridad, imparcialidad y publicidad ${ }^{49}$.

El Sistema de Compra Pública está compuesto, entre otras, por la Ley 80 de 1993, la Ley 1150 de 2007, la Ley 1474 de 2011, la Ley 1712 de 2014, el Decreto 019 y los decretos 1081 y 1082 de 2015. La interpretación y aplicación de todas las disposiciones incluidas en esos cuerpos normativos están orientadas por los principios rectores de la contratación, así como los principios de la función administrativa ${ }^{50}$.

Los principios que rigen la contratación estatal se orientan a garantizar el interés general mediante el cumplimiento de fines estatales para asegurar la continua y eficiente prestación de los servicios públicos y la efectividad de

Ricardo Rivero Ortega, "Corrupción y contratos públicos: las respuestas europea y latinoamericana", en Eduardo Fabián Caparros y Nicolás Rodríguez García (coords.), La corrupción en un mundo globalizado: análisis interdisciplinar, Salamanca: Ratio Legis, 2004, p. 111.

50 Luis Guillermo Dávila Vinueza, Régimen jurídico de la contratación estatal, Bogotá: Legis Editores, 2016, p. 32 
los derechos e intereses de los administrados, así como la correcta ejecución de recursos públicos.

Ahora bien, los principios que ocupan un papel fundamental en este escrito son los de transparencia y publicidad, pues buscan garantizar la moralidad de la contratación y la imparcialidad de la Administración en la escogencia de contratistas ${ }^{51}$.

El principio de transparencia invita a quienes intervienen en los procesos de selección a actuar de manera clara, pública e imparcial, con el fin de garantizar la igualdad de oportunidades y la selección objetiva. La jurisprudencia y la doctrina han dotado de contenido este principio indicando que tienen distintas manifestaciones, como, por ejemplo: a) la garantía de aplicación de la regla general de selección de contratistas del Estado como la licitación pública y, en todo caso, la definición de modalidades de selección como la selección abreviada y el concurso de méritos para garantizar la escogencia de la mejor propuesta ${ }_{i} b$ ) el definir requisitos mínimos objetivos necesarios para participar en un proceso de selección ${ }^{52}$; y c) el establecer reglas objetivas, claras y completas que permitan confeccionar las ofertas de los proponentes $y$, en ese sentido, garanticen la escogencia de la propuesta más favorable, entre otros.

Ahora bien, el principio de publicidad ${ }^{53}$ en el terreno de la contratación estatal encuentra casi siempre su desarrollo al interior del principio de transparencia; sin embargo, con el tiempo, este principio ha tomado fuerza y protagonismo de manera independiente. El Código de Procedimiento Administrativo y de la Contencioso Administrativo establece que

en virtud del principio publicidad, las autoridades darán a conocer al público y a los interesados, en forma sistemática y permanente, sin que medie petición alguna, sus actos, contratos y resoluciones, mediante las comunicaciones, notificaciones y publicaciones que ordene la ley, incluyendo el empleo de tecnologías que permitan difundir de manera masiva tal información de conformidad con los dispuesto en este Código ${ }^{54}$.

Por su parte, la Corte Constitucional, en la sentencia C-646 de 2000, ha dicho que el principio de publicidad facilita el control ciudadano de las decisiones

51 Juan Ángel Palacio Hincapié, La contratación de las entidades estatales, 8. ${ }^{\circ}$ ed., Bogotá: Librería Jurídica Sánchez R., 2020, p. 70.

52 Consejo de Estado, Sala de lo Contencioso Administrativo, Sección Tercera, Consejera Ponente: Stella Conto Díaz del Castillo, radicación 38339.

53 Nathalia Andrea Urrego Jiménez. "Principios de la Contratación Estatal", en: Juan David Duque y Luisa Vanegas (eds.), GPS en Contratación Pública, Bogotá: Tirant lo Blanch, 2019, pp. 121-226. "El principio de publicidad en la contratación estatal hace referencia a que todos los documentos expedidos y allegados en el marco de un proceso de contratación deben ser de público conocimiento", p. 122.

54 Ley 1437 de 2011, artículo 3, numeral 9. 
de las autoridades, permite el ejercicio de varios derechos fundamentales y contribuye de manera esencial al adecuado desarrollo y realización de los fines del Estado ${ }^{55}$. De manera que la finalidad e importancia de publicar los contratos de la Administración es realizar una comunicación masiva que permita informar, persuadir y conseguir un comportamiento determinado de las personas que reciben la información ${ }^{56}$.

\subsection{El Sistema Electrónico para la Contratación Pública (Secop)}

La Ley 80 de 1993 establecía inicialmente que los contratos estatales debían cumplir con unas formalidades, una de estas era el deber de publicación del contrato; así las cosas, la publicación de los contratos se realizaba en el Diario Único de contratación que se encontraba en un acápite específico del Diario Oficial o Gaceta Oficial.

Con la expedición de la Ley 1150 de 2007, que modificó el artículo 3 del Estatuto General de Contratación de la Administración Pública, en el sentido de ordenar al Gobierno Nacional el desarrollo del Sistema Electrónico para la Contratación Pública (SECOP), "el Gobierno Nacional desarrollará el Sistema Electrónico para la Contratación Pública: c) contará con la información oficial de la contratación realizada con dineros públicos, para lo cual establecerá los patrones a que haya lugar y se encargará de su difusión a través de canales electrónicos".

Cuando la Corte Constitucional tuvo oportunidad de pronunciarse sobre las normas contenidas en la Ley 1150 de 2007 en la sentencia C-259 de 2008, resaltó que en el desarrollo de todos los sistemas electrónicos de información que se adelanten, el principio orientador de la actividad es el principio de publicidad, por cuanto es este el que responde al derecho que tienen los ciudadanos de conocer las actuaciones de la Administración, y que en la misma medida ellos estén previstos de las herramientas para entender dicha información ${ }^{57}$.

Así las cosas, actualmente el sistema de información en materia de la contratación pública es el Sistema Electrónico de Contratación Pública (SECOP), que "es el medio de información oficial de toda la contratación realizada con dineros públicos. El SECOP es el punto único de ingreso de información para las entidades que contratan con cargo a recursos públicos, los entes de control y ciudadanía en general" ${ }^{\prime \prime 8}$.

55 Corte Constitucional, Sala Plena, sentencia C-646 del 31 de mayo de 2000, expediente: D-2652.

56 Corte Constitucional, Sala Plena, sentencia C-384 del 13 de mayo de 2003, expediente D-4312.

57 Corte Constitucional, Sala Plena, sentencia C-259 del 11 de marzo de 2008, expedienteD-6893.

58 Agencia Nacional de Contratación Pública - Colombia Compra Eficiente, Circular Externa Única, Bogotá, 16 de abril de 2019, pp. 9. Disponible en línea: https://www. 
El Decreto 019 de 2012, por medio del cual se dictaron normas para suprimir o reformar regulaciones, procedimientos y trámites innecesarios existentes en la Administración pública, eliminó el Diario Único de Contratación y en su lugar se dispuso la obligación de publicar todos los contratos estatales en el Sistema Electrónico para la Contratación Pública (SECOP), administrado por la Agencia Nacional de Contratación Pública ${ }^{59}$.

La disposición que se refería a la eliminación del diario único de contratación fue demanda ante la Corte Constitucional ${ }_{i}$ el tribunal se pronunció mediante la sentencia C-711 de 2012 y sostuvo que la publicación de los contratos es parte fundamental para la finalización del proceso de selección y en general para el procedimiento de contratación ${ }^{60}$. Explicó que lo importante de la medida no era establecer si la publicación se hacía de manera escrita o electrónica, sino que, en efecto, la medida permitiera cumplir con la finalidad de hacer público el conocimiento de dichos actos de la actuación contractual de la Administración:

La disposición acusada no suprime el deber de publicar el contrato estatal, sino que suprime una forma de realizarlo, eliminando la publicación en un medio escrito como el Diario Único de Contratación y optando por un medio electrónico, no impreso -Sistema Electrónico de Contratación Estatal (SECOP)-, que cumple la misma finalidad de hacer público el conocimiento de dichos actos de la actuación contractual de la administración.

En aquella oportunidad (en la sentencia C-711 de 2012), la Corte identificó las condiciones necesarias para la publicación y difusión de la información relativa a los procesos de contratación en Colombia:

- La imparcialidad y transparencia en el manejo y publicación de la información, en especial de las decisiones adoptadas por la Administración.

- La oportuna y suficiente posibilidad de participación de los interesados en el proceso contractual, así como los órganos de control.

colombiacompra.gov.co/sites/cce_public/files/cce_circulares/cce_circular_unica.pdf [fecha de consulta: 27 de febrero de 2020].

59 Decreto 019 de 2012, artículo 223: "Eliminación del Diario Único de Contratación. A partir del primero de junio de 2012, los contratos estatales solo se publicarán en el Sistema Electrónico para la Contratación Pública (SECOP) que administra la Agencia Nacional de Contratación Pública - Colombia Compra Eficiente. En consecuencia, a partir de dicha fecha los contratos estatales no requerirán de publicación en el Diario Único de Contratación y quedarán derogados el parágrafo 3 del artículo 41 de la Ley 80 de 1993, los artículos 59, 60, 61 y 62 de la Ley 190 de 1995 y el parágrafo 2 del artículo 3 de la Ley 1150 de 2007".

60 Corte Constitucional, Sala Plena, sentencia C-711 del 12 de septiembre de 2012, expediente: D-8971. 
- El conocimiento oportuno de la información relativa a la contratación estatal, que garantice los derechos constitucionales a la defensa, el debido proceso y el acceso a los documentos públicos.

En consecuencia, la Agencia Nacional de Contratación Pública - Colombia Compra Eficiente expidió la Circular Externa n. ${ }^{\circ} 1$ del 21 de junio de 2013, en la que recordó a las entidades del Estado el deber de publicar oportunamente su actividad contractual en el Sistema Electrónico de Contratación Pública, sin que para ello fuera determinante su régimen jurídico, naturaleza jurídica o la pertenencia a una u otra rama del poder ${ }^{61}$.

La Ley de Transparencia y del Derecho de Acceso a la Información consagró la información mínima obligatoria para procedimientos, lineamientos y políticas en materia de adquisiciones y compras, así como todos los datos de adjudicación y ejecución de contratos, incluidos concursos y licitaciones. Allí se identificaron entre los principios orientadores del derecho de acceso a la información pública el principio de "máxima publicidad". Este principio establece que "toda la información en posesión, bajo control o custodia de un sujeto obligado es pública y no podrá ser reservada o limitada sino por disposición constitucional o legal"62.

El Consejo de Estado se pronunció sobre una solicitud de medidas cautelares en el marco de la solicitud de nulidad simple, en esa oportunidad la Sección Tercera, en Auto del 14 de agosto de 2017. El consejero ponente Jaime Orlando Santofimio Gamboa expresó que la obligación prevista en la Circular Externa $\mathrm{n}^{\circ}{ }^{\circ} 1$ se ajusta a la normativa superior por considerar que el literal c del artículo 3 de la Ley 1150 de 2007 ordena a todos aquellos que contratan con dineros públicos la obligación de suministrar información veraz, autentica y completa en el SECOP, y en la línea argumentativa de la decisión se precisó como límite a la obligación de publicar aquellas actividades que sean contratadas con recursos diferentes a los recursos públicos ${ }^{63}$.

61 Agencia Nacional de Contratación Pública - Colombia Compra Eficiente, Circular Externa n. ${ }^{\circ}$, Bogotá, 21 de junio de 2013. Disponible en línea: https://www.colombiacompra. gov.co/sites/cce_public/files/cce_circulares/20130621circular1 publicacionensecop.pdf [fecha de consulta: 27 de febrero de 2020].

62 Ley 1712 de 2014, por medio de la cual se crea la Ley de Transparencia y del Derecho de Acceso a la Información Pública Nacional y se dictan otras disposiciones, artículo 2 : "Principio de máxima publicidad para titular universal. Toda información en posesión, bajo control o custodia de un sujeto obligado es pública y no podrá ser reservada o limitada sino por disposición constitucional o legal, de conformidad con la presente ley".

63 Consejo de Estado, Sala de lo Contencioso Administrativo, Sección Tercera, Subsección C, Bogotá, 14 de agosto de 2017. Radicación número: 11001-03-26-000-2017-00031. 00 (58.820): "resulta razonable concluir, en esta oportunidad, que en virtud del deber de información prescrito en el literal c) del artículo 3 o de la Ley 1150 de 2007, los sujetos obligados bajo tal norma [todos los que realizan contratación con dineros públicos] deben suministrar información sobre su contratación en términos veraces, auténticos y completos en el sistema electrónico SECOP, lo que incluye, entonces, todo acto que sea 
Posteriormente, en la Circular Externa Única, se reiteró en el numeral 1.1 que las entidades deben publicar su actividad contractual en el SECOP ${ }^{64}$. La Subdirección de Gestión Contractual de Colombia Compra Eficiente emitió el Concepto unificado n. ${ }^{\circ} 03$ de 2020, en el que abordó la importancia del principio de publicidad de la actividad contractual de todas las entidades que administran o manejan recursos públicos, en el que señaló: "el derecho de acceso a la información pública o de interés público permite a toda persona, sin necesidad de acreditar calidad, interés o condición particular, conocer la existencia de información pública, acceder a la misma y difundirla o publicarla, según su interés ${ }^{165}$.

Por todo lo anterior, es claro que los actos de corrupción en general tienen la capacidad de generar desconfianza e inestabilidad en los campos que permea; no obstante, la corrupción en el sector público y, en específico, lo que incumbe a la contratación de las entidades del Estado tienen un mayor impacto por tratarse de la gestión de recursos públicos.

Es ahí donde los principios de transparencia y publicidad adquieren relevancia, pues asegurar su aplicación y cumplimiento garantizan la libre concurrencia, materializando el deber de selección objetiva que tiene como manifestación más simple la selección de la mejor oferta para la Administración. Cuando un proceso de selección adolece de actos corruptos, el principio de publicidad surte efectos cuando se presenta denuncias y observaciones respecto de dichos procesos, permitiendo así a los ciudadanos ejercer su derecho de participación e intervención en las actividades de la Administración.

De otra parte, estos principios permiten constar el cumplimiento del derecho constitucional al debido proceso, y es de resaltar que en vigencia del SECOP I, las entidades solo podían realizar la publicación de documentos en la plataforma ${ }_{i}$ es decir, que era una plataforma netamente de publicación, mientras que el SECOP II está dirigida a permitir las transacciones entre las entidades y los particulares de manera electrónica. Esto le permite a los interesados establecer el cumplimiento del debido proceso en todas las actuaciones que giran en torno a un proceso de selección.

expresión de ejercicio o despliegue de actividad contractual". Y es que, si se quiere en términos más detallados el literal c del artículo 3 de la ley en comento responde claramente las siguientes inquietudes: ¿quiénes están obligados?, los que realizan contratación con dineros públicos; ¿en razón de qué están obligados?, en razón al manejo de tales recursos públicos y no por razón diferente; ¿cuál es el límite o la extensión de ese deber?, única y exclusivamente comprende la información relativa a lo que sea objeto de contratación con recursos públicos, se excluyen de allí la que se realice con otras fuentes; y ¿dónde se debe surtir ese deber de información?, por conducto del sistema electrónico SECOP.

64 Agencia Nacional de Contratación Pública - Colombia Compra Eficiente, Circular Externa Única, óp. cit.

65 Agencia Nacional de Contratación Pública - Colombia Compra Eficiente, Concepto Unificado CU-003 de 2020, Bogotá. 
En consecuencia, el cumplimiento por parte de las entidades estatales de publicación de la actividad contractual que desarrollan es una herramienta que permite a la Administración adelantar actividades de control sobre dichos procesos y contratos. Esto es de suma importancia porque cuando la corrupción incide en el ocultamiento sistemático y reiterado de información, restringiendo el ejercicio del poder democrático y dificultándole cumplir con el deber de transparencia, se pone en riesgo la concreción de los derechos de los ciudadanos ${ }^{66}$.

\section{CONCLUSIONES}

La corrupción es un fenómeno multidisciplinario que afecta la economía, la política, el ordenamiento jurídico y la sociedad en general. Este fenómeno impacta de manera negativa la esfera de la contratación de la Administración en virtud de los altos recursos que implica su actividad. Como se puso de presente, los gobiernos de los últimos treinta años han expedido una serie de normas a manera de lucha contra este fenómeno; sin embargo, los esfuerzos, aunque grandes, se presentan insuficientes ante un fenómeno que muta de manera rápida ${ }_{i}$ en otras palabras, la lucha contra la corrupción no es efectiva con la sola expedición de normas.

Así mismo se concluye que las causas y escenarios de corrupción en Colombia se presentan diferentes a las de otros países de la región, y, adicionalmente, han permanecido en el tiempo haciendo somera la aplicación eficiente de la normativa. En esa medida, la transparencia y la publicidad de la información que comprenden los procesos y procedimientos relativos a la actividad contractual del Estado se consolidan como herramientas fundamentales e imprescindibles en la lucha contra la corrupción, pues la publicación de los documentos del proceso y del contrato mismo permite a los interesados analizar la forma como las entidades gestionan y ejecutan los recursos públicos. Esto permite generar confianza entre los administrados y las entidades, disminuyendo el escenario de corrupción y ampliando el espectro de participación y confluencia de competencia en el mercado.

66 Michael Johnston, Political corruption and public policy in America, Monterrey: Brooks/Cole, 1982, p. 199. 


\section{BIBLIOGRAFÍA}

\section{DOCTRINA}

Agencia Nacional de Contratación Pública - Colombia Compre Eficiente. Circular Externa n. ${ }^{\circ}$ 1, Bogotá, 21 de junio de 2013. Disponible en línea: https://www. colombiacompra.gov.co/sites/cce_public/files/cce_circulares/20130621circular1 publicacionensecop.pdf [fecha de consulta: 27 de febrero de 2020].

Agencia Nacional de Contratación Pública - Colombia Compra Eficiente. Circular Externa Única, Bogotá, 16 de abril de 2019. Disponible en línea: https://www. colombiacompra.gov.co/sites/cce_public/files/cce_circulares/cce_circular_unica. pdf [fecha de consulta: 27 de febrero de 2020].

Agencia Nacional de Contratación Pública - Colombia Compra Eficiente. Concepto Unificado CU-03, Bogotá.

Ann Elliott, Kimberly. La corrupción en la economía global. México: Editorial Limusa, 2001.

Castro Cuenca, Carlos Guillermo. Corrupción y delitos contra la Administración pública. Bogotá: Universidad del Rosario, 2009.

Cárdenas, Mauricio; Steiner, Roberto. Corrupción, crimen y justicia. Una perspectiva económica. Bogotá: Tercer Mundo Editores, 1998.

Cartolano Schiaffino, Mariano J. La corrupción: aproximación teórica. Bogotá: Leyer, 2009.

Cepeda Ulloa, Fernando. La corrupción administrativa en Colombia diagnóstico y recomendaciones para combatirla. Bogotá: Contraloría General de la República. 1994.

Cepeda Ulloa, Fernando. Corrupción. Bogotá: Cuéllar Editores, 2017.

Dávila Vinueza, Luis Guillermo. Régimen jurídico de la contratación estatal. Bogotá: Legis Editores, 2016.

ESCOBAR LÓPEZ, ÉDGAR. Estatuto anticorrupción Ley 190 de 1995. Estudio técnico-jurídico integro. Medellín: Biblioteca Jurídica Diké, 1996.

Fedesarrollo. La corrupción en Colombia. Bogotá: Tercer Mundo, 1997.

García Villegas, Mauricio; Revelo Rebolledo, Javier Eduardo. Estado alterado. Clientelismo, mafias y debilidad institucional en Colombia. Bogotá: DeJusticia, 2010.

Gil Botero, Enrique. Teoría general de los contratos de la Administración pública, Bogotá: Legis, 1999. 
Johnston, Michael. Political Corruption and public policy in America. Monterrey: Brooks/ Cole, 1982.

Klitgaard, Robert. Controlling corruption. Berkeley: University of California Press, 1988.

Laporta, Francisco J.; Álvarez, Silvina. La corrupción política. Madrid: Alianza Editorial, 1997.

LeAL-HeRnÁNDEZ, ABELARdo. La corrupción administrativa en la contratación pública. Bogotá: s.e., 2016.

Martínez Cárdenas, Edgar Enrique; Ramírez Mora, Juan Manuel. "La corrupción en la contratación estatal colombiana una aproximación desde el neoinstitucionalismo". Reflexión Política, vol. 8, n. ${ }^{\circ}$ 15, 2006.

Misas Arango, Gabriel. La lucha anticorrupción en Colombia. Bogotá: Contraloría General de la República, 2005

Newman Pont, Vivian; Ángel Arango, María Paula. Estado del arte sobre la Corrupción en Colombia. Bogotá: Dejusticia, 2017.

Palacio Hincapié, Juan Ángel. La contratación de las entidades estatales, 8. ed. Bogotá: Librería Jurídica Sánchez R., 2020.

Pring, Coralie; Vrushi, Jon. Barómetro global de la corrupción América Latina y el Caribe 2019. Opiniones y experiencias de los ciudadanos en materia de corrupción. Transparency International, 2019. Disponible en línea: https://transparenciacolombia. org.co/wp-content/uploads/gcb-lac-report-web.pdf [fecha de consulta: 18 de febrero de 2020].

Rivero Ortega, Ricardo. "Corrupción y contratos públicos: las respuestas europea y latinoamericana". En Eduardo Fabián Caparros y Nicolás Rodríguez García, La corrupción en un mundo globalizado: análisis interdisciplinar. Salamanca: Ratio Legis, 2004.

Tovar González, LeOnARdo. Ética social y corrupción pública. La corrupción en Colombia. Bogotá: Red de Solidaridad Social, 1997.

Urrego Jiménez, Nathalia Andrea. "Principio de la contratación estatal". En Juan David Duque y Luisa Vanegas (eds.), GPS en Contratación Pública. Bogotá: Tirant lo Blanch, 2019.

\section{JURISPRUDENCIA}

Consejo de Estado, Sala de lo Contencioso Administrativo, Sección Tercera Subsección C, 14 de agosto de 2017. Radicación número: 11001-03-26-000-00031-00(58.820). 
Corte Constitucional, Sala Plena, Sentencia C-449 del 9 de julio de 1992. Expediente D-033.

Corte Constitucional, Sala Plena, Sentencia C-646 del 31 de mayo de 2000. Expediente D-2652

Corte Constitucional, Sala Plena, Sentencia C-384 del 13 de mayo de 2003. Expediente D-4312.

Corte Constitucional, Sala Plena, Sentencia C-932 del 9 de noviembre de 2007. Expediente D-6794.

Corte Constitucional, Sala Plena, Sentencia C-259 del 11 de marzo de 2008. Expediente- D-6893

Corte Constitucional, Sala Plena, Sentencia C-711 del 12 de septiembre de 2012. Expediente: D- 8971

Corte Constitucional, Sala Plena, Sentencia C-207 del 16 de mayo de 2019. Expediente D-12877. 